\title{
A VIA CRUCIS DO CORPO DA MULHER: TRAJETOS DE VIOLÊNCIA NA LITERATURA BRASILEIRA SOB A ÓTICA DOS DIREITOS HUMANOS DAS MULHERES
}

\author{
Hilda Helena SoARes Bentes ${ }^{1}$
}

\begin{abstract}
RESUMO: Propõe-se analisar os trajetos de violência contra a mulher na literatura brasileira sob a perspectiva dos direitos humanos da mulher. Busca-se uma articulação entre a literatura, a filosofia e o direito. Numa abordagem interdisciplinar, o artigo examina a constituição de um sujeito do direito, através do conceito de capacidade, elaborado por Paul Ricoeur, aplicável à condição ainda precária da mulher. Examinam-se alguns textos literários significativos sobre a violência praticada contra a mulher, começando por uma reflexão sobre o pensamento de Lima Barreto, cujo grito de inconformismo contra os crimes passionais cometidos pelos maridos e parentes é ecoado em várias crônicas no início do século vinte. Percorre-se igualmente uma literatura de autoria feminina, surgida especialmente a partir dos anos 70, refletindo, de forma pungente, a persistente brutalidade em face da mulher. Cuida-se da promoção dos direitos humanos no tocante à violência contra a mulher, e a luta da mulher por reconhecimento, debate ainda necessário apesar dos progressos sociais e jurídicos alcançados.
\end{abstract}

Palavras-ChaVe: sujeito do direito; literatura brasileira; violência de gênero; direitos humanos.

\section{INTRODUÇÃO}

Estabelece-se neste artigo uma intersecção entre filosofia, literatura e direito como possibilidade de captar os trajetos de violência contra a mulher na literatura brasileira sob a perspectiva dos direitos humanos da mulher. A conexão entre a filosofia e literatura, com extensão ao direito, revela a importância da interdisciplinaridade como apreensão do humano e

1 Doutora em Filosofia do Direito pela Pontifícia Universidade Católica de São Paulo (PUCSP). Professora do Programa de Mestrado em Direito da Universidade Católica de Petrópolis/RJ (PPGD/UCP). Líder do Grupo de Pesquisa Fundamentos da Justiça e dos Direitos Humanos (CNPq) e Coordenadora do Projeto de Pesquisa Direitos Humanos e Literatura: alteridade e identidade narrativa na visão de Paul Ricoeur. Petrópolis, RJ, $\begin{array}{lll}\text { Brasil. } & \text { CV Lattes: http://lattes.cnpq.br/7621671933218419. E-mail: }\end{array}$ hildabentes@uol.com.br. 
como desenvolvimento de uma consciência crítica dos fenômenos sociais. A primeira parte do desenvolvimento será dedicada a explicitar a relação entre filosofia, direito e literatura de forma a configurar a perspectiva que se pretende desenvolver neste trabalho, qual seja a literatura como expressão artística das problemáticas existenciais, reveladora da exploração do ser humano e da possibilidade de humanização.

Indaga-se se o discurso sobre os Direitos Humanos, seja teórico ou prático, constitui a expressão exata das graves violações perpetradas contra a pessoa humana. Ele é revelador da extrema vulnerabilidade em que o homem ou a mulher encontra-se quando despojado(a) de sua humana condição? É indubitável que o discurso sobre Direitos Humanos, desde as célebres Declarações históricas, pauta-se sobre uma agenda de direitos inalienáveis do ser humano, e desperta, sobretudo, sentimentos de exaltação aos direitos proclamados. No entanto, vertentes da história do pensamento ocidental interpretam as declarações dos direitos do homem como abstratas, ou com conteúdo marcadamente liberal, o que não preencheria os verdadeiros anseios de homens e mulheres à margem de direitos reconhecidos.

Propõe-se examinar a constituição de um sujeito do direito capaz de respeito e estima, através do conceito de capacidade, elaborado por Paul Ricoeur. Avalia-se a formação do homem capaz, conforme explicitado no texto "Quem é o sujeito do direito?", em $O$ justo 1, bem como em $O$ simesmo como um outro. A noção de capacidade constitui o marco teórico central para a compreensão da formação do homem, o que será examinado na segunda parte do desenvolvimento deste artigo.

A leitura de textos literários, além da análise dos elementos constitutivos inerentes à composição literária, tem o fito de evidenciar as injustiças sociais e desumanidades a que estão subjugados aqueles que não detêm o poder de falar e de narrar a sua história, consoante os padrões culturais reputados válidos para a inserção na comunidade social e política. Nesse aspecto, afigura-se pertinente a leitura das crônicas de Lima Barreto, que se manifesta, de forma contundente, contra o massacre de mulheres em várias crônicas no início do século vinte, o que será visto na terceira parte do desenvolvimento. 
Parte-se da indagação de como as conquistas legais dos direitos das mulheres ainda não conseguiram extirpar toda uma prática cultural de depreciação da mulher. As denúncias feitas por Lima Barreto são sinais eloquentes, porém insuficientes para conter a fúria destrutiva contra $\mathrm{o}$ corpo da mulher. Persistem ainda os vestígios de uma cultura de violência contra a mulher, o que desafia a lei e os costumes atuais.

A quarta parte irá analisar a parte relativa à literatura de autoria feminina, tendo sido denominada "A via crucis do corpo da mulher: trajetos de violência na literatura de Clarice Lispector, Lygia Fagundes Telles, Lya Luft e Marina Colasanti”. São fragmentos de violência praticada contra a mulher em decorrência de uma cultura de violação aos direitos fundamentais da mulher, centrada na dominação masculina, e que impõe papéis definidos de comportamento.

Cuida-se da promoção dos direitos humanos no tocante à violência contra a mulher, debate ainda necessário apesar dos progressos sociais e jurídicos alcançados. O referencial metodológico busca subsídios teóricos e literários para a construção de um canal de discussão importante para a formação de uma efetiva cultura calcada nos Direitos Humanos, modulando a linguagem e, principalmente, os sentimentos dos futuros aplicadores do direito.

\section{LIMITES E ALCANCE DO ENLACE TEÓRICO, LITERÁRIO E JURÍDICO}

Delimitar as fronteiras entre a filosofia, a literatura e o direito constitui uma difícil tarefa a ser empreendida. São campos de saber distintos e apresentam particularidades que os distinguem e qualificam por parâmetros por vezes considerados antagônicos. Ressalte-se que sempre existiu uma querela entre a filosofia e a literatura, revelada de forma contundente por Platão em A república, ao expulsar os poetas e os trágicos da comunidade política, elaborada a partir de um modelo educacional baseado num método racional, descritivo, que tornariam o homem capaz de desenvolver plenamente as suas capacidades cognitivas (Platão, 1996, livro X, 605d, p. 472-3; Havelock, 1996, p. 19-35).

A literatura pode servir como um instrumento poderoso para a decifração da condição humana, o que constitui um recurso valioso para a compreensão dos direitos humanos na sua dimensão libertadora (Fachin, 
2007, p. 19). Nesse aspecto que nos interessa, o discurso jurídico coloca-se na rota ${ }^{2}$ de revelar as instâncias de poder instituído e os clamores de justiça, fundamentalmente obra de um sistema social ainda predominantemente injusto. No entanto, deve-se advertir que o texto literário tem especificidades artísticas próprias, intransponíveis, não podendo ser confundido com uma literatura dirigida, de viés ideológico, e que serve de meio de dominação e inculcação de ideias preconcebidas.

A literatura é por essência emancipadora e ultrapassa uma visão meramente instrumental. Busca-se ir além das concepções comumente estabelecidas entre a literatura e a filosofia, ou entre a literatura e o direito, concentrando-se no direito à literatura, tal qual proposto por Antonio Candido (2011, 171-193), como direito incontornável da formação educacional e caminho de descobrimento das obscuras razões que levam o ser humano a praticar tantas iniquidades. Daí a sua imbricação com a questão dos direitos humanos. Vale dizer, na apreciação de Antonio Candido, vivemos numa época ainda marcada pela barbárie (2011, p. 172173) e pela "irracionalidade do comportamento" (1989, p. 107), sendo indispensável que os direitos humanos sejam pensados com relação ao próximo; sem o outro como referência, qualquer tentativa de falar sobre os direitos do homem torna-se infrutífera (Candido, 1989, p. 110).

Como crítico literário, Antonio Candido concebe a literatura desempenhando três funções primordiais e simultâneas: como construção da estrutura e significado literários; como forma de expressão; e, como forma de conhecimento (2011, p. 178-179). Donde a literatura constituir-se em aprendizado, afirmando Candido que "toda obra literária é antes de mais nada uma espécie de objeto, de objeto construído; e é grande o poder humanizador desta construção, enquanto construção" (2011, 179, grifos do autor). Depreende-se desta passagem que o texto literário é uma criação do artista, mas que propicia desvelamentos sobre a natureza humana e a vida social na medida em que desperta reflexões transformadoras. É, de fato, um aprendizado, que conduz o leitor atento na rota de um processo de

\footnotetext{
Melina Girardi Fachin denomina a Parte I de seu estudo Direito e literatura: em busca das rotas das narrativas emancipatória” (2007, p. 21), tendo em vista a possibilidade do diálogo interdisciplinar entre os discursos literário e o jurídico como meio de alcançar narrativas fecundas entre os dois campos de saber, e não somente utilizando a literatura como mero adorno para ampliar os recursos retóricos do aplicador do direito.
} 
humanização. Nesse aspecto, Antonio Candido fala no perigo de "mutilar a personalidade" (2011, p. 188) caso o acesso à literatura fosse restringido do processo educacional do ser humano. Expõe a relação entre a literatura e os direitos humanos como via necessária para o aperfeiçoamento da nossa humanidade:

Acabei de focalizar a relação da literatura com os direitos humanos de dois ângulos diferentes. Primeiro, verifiquei que a literatura corresponde a uma necessidade universal que deve ser satisfeita sob pena de mutilar a personalidade, porque pelo fato de dar forma aos sentimentos e à visão do mundo ela nos organiza, nos liberta do caos e portanto nos humaniza. Negar a fruição da literatura é mutilar a nossa humanidade. Em segundo lugar, a literatura pode ser um instrumento consciente de desmascaramento, pelo fato de focalizar as situações de restrições dos direitos, ou de negação deles, como a miséria, a servidão, a mutilação espiritual. Tanto num nível quanto no outro ela tem muito a ver com a luta pelos direitos humanos. (2011, p. 188, grifos nossos).

Demonstrada a importância de pensar a literatura na interface da filosofia e do direito, defronta-se, por outro lado, segundo Jaime Ginzburg (2012, p. 190-191), com a dificuldade de formular as enunciações que expressem os sentimentos, as vivências, e, consequentemente, os direitos. Ou seja, a linguagem - nosso veículo de comunicação linguística, literária caracteriza-se pela imprecisão e pela equivocidade, o que pode gerar uma série de incompreensões e dubiedades. Ginzburg refere-se a Ludwig Wittgenstein como o filósofo que refletiu de maneira profunda acerca da linguagem e dos sentimentos, especialmente sobre a dor, tal qual exposto nas Investigações filosóficas (2005, § 244 et seq.). Dito de outra forma, só poderá haver trocas de experiências e, portanto, comunicação e reconhecimento, na proporção da existência de real compartilhamento da dor alheia.

A segunda filosofia de Wittgenstein constitui uma reviravolta na concepção esboçada na primeira fase, seguindo a antiga tradição de atribuir uma função meramente designativa da linguagem, logo redutora das múltiplas possibilidades da linguagem humana. Não se cuida mais de buscar uma essência última, capaz de designar a verdadeira natureza das coisas; ao revés, objetiva-se espelhar o mundo através de um olhar perscrutador, hábil em decifrar as conexões existentes nos vários contextos em que as ações e os atos de fala se entrecruzam. Mergulha-se agora na 
indeterminação da linguagem, na concretude das situações em que as palavras expressam multifários sentidos.

Segue-se que a enunciação dos direitos - dos direitos humanos, em especial - passa a ser problemática se desvinculada de uma partilha de experiências assentada numa relação sincera de reconhecimento (Ginzburg, 2012, p. 190). Segundo Ginzburg, "o problema das relações entre literatura e direitos humanos tem ligação com omissões, lacunas e silenciamentos em discursos institucionais, jurídicos e científicos" (2012, p. 201). A literatura auxilia-nos na compreensão de linguagens assimétricas, ocultas, vozes silenciosas que a obra literária deixa transparecer. O aporte filosófico de Paul Ricoeur, na constituição do sujeito capaz, não deixa dúvida sobre a privação de direitos que sofrem as mulheres aviltadas dos seus direitos elementares, longe de serem sujeitos do direito e, portanto, autoras de sua história.

\section{A CONSTITUIÇÃO DO SUJEITO CAPAZ}

Devemos considerar a constituição do juízo que implica o reconhecimento de um sujeito capaz, digno de estima e respeito. Para Paul Ricoeur, o sujeito capaz deriva da dimensão ética e moral do si-mesmo (1991, passim; Ricoeur, 1996, p. 163-180), tornando o homem passível de imputação ético-jurídica, conforme se depreende igualmente do texto “Quem é o sujeito do direito?” da obra O justo 1 (2008, p. 21-31). Para atingir o fim último da formação de um sujeito de pleno direito, Ricoeur chama a atenção para a pergunta Quem?, que irá desencadear questionamentos na direção da identificação do sujeito.

Partindo dessa primeira interrogação, passa-se para a noção de sujeito capaz. O conceito de capacidade pressupõe a condição de o indivíduo ser o autor de suas ações, a quem serão atribuídos direitos e deveres decorrentes desse "poder-fazer" (2008, p. 23), ou seja, do agir livre e consciente segundo seu juízo. A ênfase de Ricoeur na pergunta Quem? demarca a possibilidade de o homem poder designar-se como autor de seus atos e, consequentemente, de sua história. Essa marca identificadora é importante para a estruturação do núcleo do si (self, ipse) e para a formação das atribuições morais e jurídicas que condicionam o agir humano, exigindo 
que o homem capaz assuma os deveres correspondentes, ou seja, venha a constituir-se em homem responsável.

Percebe-se que o entendimento de sujeito capaz suscitado pela pergunta Quem? desloca-se para o verbo "eu posso", nos seguintes desdobramentos: "poder dizer", "poder fazer", "poder narrar e narrar-se". Destaque-se que existe uma relação de complementariedade entre a pergunta Quem? e a locução verbal "Eu posso" na medida em que o ponto nuclear da indagação é a identificação do sujeito da fala, da ação e da narrativa. Vale dizer, busca-se a autoria desses predicados, o homem capaz de construir as suas próprias enunciações e, portanto, a sua identidade pessoal.

No que se refere à trajetória percorrida pelo indivíduo no desenvolvimento da identidade pessoal e da capacidade, Ricoeur denomina esse processo de "hermenêutica da pessoa" (1996, p. 164), especificando quatro estratos, que compõem uma estrutura ternária: linguagem, ação, narrativa, vida ética, correspondentes às proposições "o homem falante, $o$ homem que age (e acrescentarei [Paul Ricoeur] o homem que sofre), o homem narrador e personagem de sua narrativa de vida, finalmente o homem responsável" (1996, p. 164).

O exame especialmente do homem falante e do homem narrador instituem uma "gramática do 'eu posso"” (2006, p. 109), assim denominado na configuração dos níveis hermenêuticos da pessoa. A primeira camada do homem falante - é crucial para a inteligibilidade da presente temática, pois coloca o homem como ser privilegiado, detentor da fala e criador de seu mundo e da sua história. Ricoeur aproxima-se da linguagem para extrair elementos esclarecedores para a sua tese, principalmente do estudo semântico e pragmático da linguagem. É nesse contexto que o ser falante adquire capacidade ao tornar-se "locutor de se designar como enunciador único de suas enunciações múltiplas” (2008, p. 26).

Importa assinalar que o plano da pragmática do discurso tem um papel fundamental na formação do homem capaz em virtude da relevância do ato ilocutório, que pressupõe a noção de engajamento do ser falante3. A

\footnotetext{
3 Cite-se o entendimento de Ricoeur a respeito do nível pragmático da linguagem: "Entendo por pragmática o estudo da linguagem em situações de discurso em que o significado de uma proposição depende do contexto de interlocução" (1996, p. 164).
} 
capacidade de colocar-se na linguagem, envolvendo-se e comprometendose no discurso, representa a afirmação de um sujeito capaz de dizer algo e de ser, ao mesmo tempo, reconhecido pelo ouvinte. A fala implica a relação com o outro, a interlocução, e, por conseguinte, o ato de reconhecer e de ser reconhecido (Ricoeur, 2008, p. 26; 1996, p. 170-171). Pressupõe a consideração da alteridade, segundo descreve Ricoeur:

A autodesignação do sujeito falante se produz em situações de interlocução nas quais a reflexividade se associa à alteridade: a palavra pronunciada por uma pessoa é uma palavra dirigida a outra; além disso, pode ocorrer de ela responder a uma interpelação vinda de outrem. Desse modo, a estrutura pergunta-resposta constitui a estrutura básica do discurso enquanto implicando locutor e interlocutor (2006, p. 111).

A noção de justiça localiza-se na direção do outro, na assunção da alteridade. Logo, Ricoeur, ao investigar quem é o sujeito do direito, está conduzindo a discussão para o nível de reconhecimento ético, meio de identificar o outro - a despeito das particularidades e das características étnicas e culturais - como uma pessoa digna de ser considerada. Analisando as implicações linguísticas próprias a essa abordagem, Ricoeur sublinha o papel de protagonista que o sujeito capaz desempenha na narrativa de sua história. Em Quem é o sujeito do direito?, Ricoeur amplia o horizonte das relações interpessoais para um plano cada vez mais abrangente:

A mesma relação triádica eu/tu/terceiro é encontrada no plano que distinguimos pela pergunta quem age?, quem é o autor da ação? A capacidade de alguém se designar como autor de suas próprias ações está de fato inserida num contexto de interação no qual o outro figura como meu antagonista ou meu coadjuvante, em relações que oscilam entre o conflito e a interação. Mas inúmeros outros estão implicados em toda empresa. Cada agente está interligado a esses outros pela intermediação de sistemas sociais de diversas ordens (2008, p. 27).

Põe-se em evidência a dimensão ética na constituição do homem capaz na medida em que a estima de si realiza-se no intercâmbio com os outros. Ricoeur nomeia solicitude o movimento do si ao encontro do outro, busca de reciprocidade e reconhecimento. A abordagem do outro como meu semelhante rompe com o ciclo da desigualdade, que cava um abismo entre os homens, os quais, guiados pela vontade de poder absoluto, estabelecem 
critérios de diferenciação baseados em falsas crenças e no desejo de dominação. Ricoeur diz que

\begin{abstract}
a petição ética mais profunda é a da reciprocidade que institui o outro como meu semelhante e eu mesmo como semelhante do outro [...] Um outro semelhante a mim, este é o voto da ética no que diz respeito à relação entre a estima de si e a solicitude (1996, p. 165).
\end{abstract}

Pretende-se extrair do pensamento ricoeuriano os elementos hermenêuticos significativos que possam secundar uma intersecção entre filosofia, literatura e direito de forma convincente para a problemática da condição da mulher, ainda alvo de uma violência irracional e incompreensível em face das conquistas jurídicas alcançadas.

\title{
RASTROS DE VIOLÊNCIA CONTRA A MULHER NAS CRÔNICAS DE LIMA BARRETO
}

Lima Barreto é um autor singular. Ele reflete de forma lúcida e firme contra os assassinatos das mulheres infiéis, ocorridos no âmbito familiar (Vasconcellos, 2014, p. 4). Na crônica "Não as matem" (Barreto, 1961b, p. 83-85), publicada em 27 de janeiro de 1915, Lima Barreto denuncia os crimes de uxoricídio, praticados pelos homens com o consentimento da sociedade. Nessa crônica, o escritor salienta que as atitudes violentas contra a mulher derivam de uma visão distorcida, pois os homens sentem-se donos das mulheres, podendo exercer sobre elas um poder ilimitado, um poder de vida ou morte (Barreto, 1961b, p. 83-84; Vasconcellos, 2014, p. 4).

Ressalta que as mulheres são também suscetíveis de alterações ao longo do tempo, podendo ser influenciadas por outras inclinações e paixões (Barreto, 1961b, p. 84). A postura de Lima Barreto choca a sociedade da época, porquanto se espera que a mulher seja totalmente submissa ao marido, ao pai, ao irmão. Afora a completa subordinação à vontade do homem, à mulher cumpre ter um comportamento recatado e pacífico, sem qualquer sinal de impetuosidade que pudesse pôr em risco a serenidade da família. Consoante Eliane Vasconcellos, “o homem, até pouco tempo, era o senhor todo-poderoso; a mulher, a fêmea submissa que administrava e/ou executava as atividades domésticas" (1999, p. 28). Ou seja, a mulher era despojada de capacidade jurídica. Tampouco era reconhecida como sujeito do direito, na concepção que lhe empresta Paul Ricoeur. 
Em outras crônicas, Lima Barreto expõe com agudeza as críticas contra as injustiças e barbaridades cometidas contra as mulheres, resquícios da antiga legislação oriunda das Ordenações Filipinas, em que ao homem era permitido matar a adúltera (Vasconcellos, 1999, p. 279; 2014, p. 2). Em Bagatelas, Lima Barreto analisa a prática antiga, desumana, e a condescendência para com os assassinos das mulheres:

Uma das sobrevivências nefastas dessa ideia medieval, aplicada nas relações sexuais entre o marido e a mulher, é a tácita autorização que a sociedade dá ao marido de assassinar a esposa, quando adúltera. No Brasil, então é fatal a sua absolvição, no júri (Barreto, 1961a, p. 168).

Percebe-se como o sentimento de impunidade até pouco tempo era tolerado pela sociedade brasileira. Os crimes contra a honra eram aceitos como argumentos incontestes nos julgamentos contra os crimes de uxoricídio. A vítima passava a ser considerada a causadora do infortúnio, em virtude de ter maculado a honra do esposo e de toda a família. Lima Barreto interroga-se qual o crime de maior gravidade - se o adultério ou o assassinato -, considerado esse ato um crime premeditado, segundo o escritor, e não um ato impulsivo como é visto pela defesa da honra do homem injuriado (Barreto, 1961a, p. 175). Eliane Vasconcellos analisa com clareza a atuação lúcida de Lima Barreto:

Com justeza, Lima Barreto compreendeu que os julgamentos objetivavam simplesmente reafirmar as normas dominantes. $\mathrm{O}$ autor percebeu, de forma clara, que aquilo que era julgado num tribunal, onde comparecia um uxoricida, não era a conduta do homem e sim a conduta sexual da mulher, ela, de vítima, para a ré. Isto ocorria porque o modelo ideal de mulher é o de esposa doce e submissa, cujas principais virtudes são o recato, a dedicação e a fidelidade. Já no homem, tais qualidades não eram primordiais. Para salvar o uxoricida, o advogado atacava a honra feminina, normalmente acusadas de desavergonhadas (2014, p. 6).

Destaque-se que a dominação masculina (Miguel; Biroli, 2013, p. 7) era imperante e alastrava-se por toda a sociedade. Era uma sociedade fechada, de papéis bem definidos, com poucas possibilidades de mudanças no quadro social. Trata-se de relações de poder que implicam uma desigualdade enorme entre os sexos. A mulher era completamente ofuscada numa sociedade que não a reconhecia como sujeito do direito. Era invisível e não considerada pessoa digna de estima e consideração. 
É importante registrar a atuação de promotores públicos da época, como Carlos Sussekind de Mendonça, Roberto Lyra, Caetano Pinto de Miranda Montenegro e Lourenço de Mattos Borges, associados ao Conselho Brasileiro de Hygiene Social, na defesa das mulheres. A finalidade precípua desse Conselho seria coibir o alto índice de assassinatos de mulheres, vítimas de crimes passionais tolerados pela sociedade do início do século passado. (Blay, 2003), como foi vista pelas crônicas de Lima Barreto. Entretanto, o Conselho não tinha por objetivo a criação de condições para a emancipação da mulher como sujeito do direito, mas da instituição familiar primordialmente. Entretanto, a existência do Conselho funcionou como um locus de mediação e de transformação para a emergência de novas ideias libertárias e para o reconhecimento da condição da mulher.

Deve-se ressaltar que o movimento liderado pelos promotores públicos tinha por escopo extinguir "a tolerância social e legal em relação aos crimes passionais", consoante afirma Susan Bessa (1999, p. 90). Ou seja, tratava-se de um crime masculino, praticado pelo marido, noivo, pais ou irmãos na hipótese de conflitos relacionados a amor e a relações sexuais. Com efeito, esse crime era praticado numa escalada sem freios, constituindo um verdadeiro "massacre de mulheres" (Bessa, 1999, p. 90), em que elas eram assassinadas com o beneplácito da sociedade e com o amparo da legislação em vigor.

É interessante apontar os objetivos do Conselho Brasileiro de Hygiene Social, conforme discorre Susan Bessa, para verificar a intenção dos promotores de justiça envolvidos na caminhada em defesa da extinção dos assassinatos das mulheres:

\begin{abstract}
expor as verdadeiras motivações (antissociais) existentes por trás dos crimes passionais; reeducar a sociedade, destruindo com isso as convenções e as crenças populares que protegiam tais criminosos; repudiar as doutrinas legais que justificavam tais criminosos; e impor rigorosamente sentenças duras como recurso necessário de intimidação coletiva. (1999, p. 90).
\end{abstract}

De fato, o Conselho logrou alcançar no início da década de trinta do século passado os objetivos almejados: penalidades aos assassinos e revisão do Código Penal de 1940, com a eliminação do fator da emoção e da paixão como excludentes da criminalização penal. Em contrapartida, deve-se assinalar que o Conselho Brasileiro de Hygiene Social - como o nome bem 
retrata - tinha por escopo "uma grande obra de higiene social" (Bessa, 1999, p. 90), com vistas a regenerar a sociedade tendo a família como alicerce principal. Às mulheres também era direcionada a campanha de higienização social no sentido de incutir-lhes valores sociais e morais para que a estrutura familiar não fosse abalada por questões passionais, que poderiam desencadear os instintos bárbaros dos homens.

Verifica-se, assim, que a mulher ainda não se constituía em um sujeito plenamente habilitado a assumir o seu papel na sociedade, vale dizer, a exercer a cidadania, como condição imprescindível para o desabrochar completo de seu intelecto e para o exercício do jogo político. Vale dizer, ainda não era reconhecida de forma plena, não alcançando o nível de humanidade que a tornaria digna de estima e de respeito.

\section{A VIA CRUCIS DO CORPO DA MULHER: TRAJETOS DE VIOLÊNCIA NA LITERATURA DE CLARICE LISPECTOR,LYGIA FAGUNDES TELLES, LYA LUFT E MARINA COLASANTI}

Busca-se, nesta seção, fazer uma breve referência a alguns textos literários que constituem uma literatura marcante nos anos setenta do século passado. São escritos por mulheres, o que não significa que são estudos feministas sobre a mulher. Ao contrário, as escritoras que serão mencionadas - Clarice Lispector, Lygia Fagundes Telles, Lya Luft e Marina Colasanti - certamente rejeitariam a qualificação de "feministas" na medida em que os textos revelam visões e estilos literários que ultrapassam uma literatura meramente voltada para a representação da violência contra a mulher. Na verdade, os estudos literários acerca dessa literatura de autoria feminina procuram retratar a "violência física e simbólica" (Gomes, 2013, p. 3) contra a mulher devido à perpetuação de um modelo perverso de dominação masculina, sem abrir mão dos ricos e sutis recursos literários que transformam essas autoras em escritoras de primeira linha no cenário da literatura brasileira contemporânea.

Parte-se, nesta pesquisa, do título da obra de Clarice Lispector: A via crucis do corpo (1998). De acordo com a explicação dada pela própria autora, são histórias "contundentes" (1998, p. 11), reveladoras de um mundo cruel e lúgubre. Indevassável e enigmático como os olhos da bilheteira de cinema, como revela Clarice. Donde a utilização do título Via 
crucis do outro por Daniela Kahn (2005) como tentativa de decifrar o outro, marcado por uma relação de alteridade que implica sempre um componente de violência. Procura-se, enfim, uma amostra da violência recorrente contra a mulher, que a despoja de sua humanidade e a expõe a um ciclo ininterrupto de ameaças contra sua integridade física e moral. Chegamos ao título do presente estudo: "A via crucis do corpo da mulher: trajetos de violência na literatura brasileira sob a ótica dos direitos humanos das mulheres", em que várias encenações sobre a brutalidade contra a mulher são vistas como uma deformidade cultural, que se arrasta por séculos, e que continua a negar a mulher o status de sujeito capaz.

Não se trata de discutir as teorias feministas que traçam a trajetória das lutas das mulheres por reconhecimento. Cuida-se, ao revés, de capturar os momentos em que a mulher ainda é exposta a um alto grau de vulnerabilidade, que a ameaça constantemente, dentro e fora do ambiente doméstico. Com efeito, Susan Moller Okin é enfática quando discute a vulnerabilidade pelo casamento, afirmando que "em aspectos cruciais o casamento estruturado pelo gênero "insere as mulheres num ciclo de vulnerabilidade socialmente causada e distintamente assimétrica” (1989, p. 138)4. Mas do que posições assimétricas, um grande contingente de mulheres ainda sofre violência doméstica, estupros, espancamentos, como melancolicamente retratado por Lya Luft em As parceiras (2015). A narradora percorre um caminho de inescapável amargura proveniente de uma história familiar atravessada pela brutalidade sofrida pela matriarca Catarina, refugiada em sua própria dor e desalento. Representa a visão do cotidiano de violência e silêncio imposto a muitas mulheres que vivem em ambientes opressores (Gomes, 2013, p. 7). Destaca-se o seguinte trecho do romance, que expressa a dor pungente da mulher ferida e humilhada:

Conseguiu sobreviver até quarenta e seis anos. O marido desistiu de lhe ensinar as artes dos bordéis, preferindo teúdas e manteúdas àquela adolescente que já lhe provocava mais medo do que desejo. Mudou-se para uma de suas fazendas, no casarão aparecia apenas como visitante temido. Minha avó ficou meio esquecida com as empregadas e uma governanta. Quando o marido irrompia naquela falsa tranquilidade, não deixava de

4 Texto no original: "in crucial respects gender-structured marriage involves women in a cycle of socially and distinctly asymmetric vulnerability". Parte da tradução foi tomada da Introdução de Luis Felipe Miguel e Flávia Biroli (2013, p. 35). 
procurar a mulher. Dava um jeito de abrirem o sótão, e entre gritos e escândalo emprenhava Catarina outra vez (2015, p. 14)

Registre-se que a edição da Lei Maria da Penha, Lei 11.340, de 2006, procura coibir a violência doméstica e familiar contra a mulher5. A lei protege a mulher contra as diversas formas de exclusão, dando-lhe amparo para que ela possa integrar-se à sociedade e exercer plenamente a cidadania. Deve-se, sem dúvida, ressaltar a importância da Lei Maria da Penha como um avanço importante no sentido da criminalização da violência doméstica e sexual. Todavia, verifica-se que o instrumento legal é insuficiente para conter o aviltamento contra a mulher, conforme advertem Luis Felipe Miguel e Flávia Biroli:

Ainda assim, permanece a tolerância a muitas das formas
de subordinação diretamente conectadas a relações de
poder nas quais as diferenças de gênero são
fundamentais. A subordinação das mulheres aos homens
na esfera doméstica está longe de ser uma realidade
superada, mas se redefine em relações nas quais a
objetificação e mesmo a exaltação da beleza feminina são
formas de controle (2013, p. 34, grifos nossos).

Por conseguinte, torna-se indispensável uma revisão profunda nos parâmetros em que se baseiam as relações de gênero. O corpo da mulher é ainda extremamente vulnerável à cupidez e à dominação masculina. Ao homem coube um comportamento agressivo no que tange à vida pública $\mathrm{e}$ ao domínio exercido sobre a mulher, pensamento ainda resistente aos princípios norteadores da modernidade. Lima Barreto assim criticava a mentalidade dos homens no início do século XX. Não se justifica que ainda existam mentes deformadas com relação ao trato com as mulheres. $\mathrm{O}$ preconceito contra a mulher rebaixa-a e torna-a um objeto de troca intercambiável. A condição física da mulher e a ideia de possessão do homem sobre o corpo da mulher aprofunda a questão da vulnerabilidade, colocando a mulher num nível crítico de desamparo. Clarice Lispector captura a situação de violência sexual sofrida por Cidinha, personagem central do conto "A língua do 'P”", que entra em desespero quando percebe, num vagão de trem, que estaria na iminência de ser estuprada e

5 Segundo informa Carlos Magno Gomes a lei "nasce da luta da farmacêutica Maria da Penha Maia, ao tentar processar seu agressor, o ex-marido Marcos Antônio Herredia, que, apesar de atentar contra sua vida duas vezes, deixando-a paraplégica, teve direito de viver em liberdade" (2013, p. 5). 
assassinada. Finge-se de prostituta para fugir aos agressores. Lê, posteriormente, já salva da sanha assassina, a manchete fatídica: "Moça currada e assassinada no trem" (1998, p. 70). Ou seja, Cidinha é retirada do trem por ter sido considerada prostituta, e entra outra mulher, vítima fatal da ação implacável dos criminosos.

O conto de Clarice Lispector, narrativa que mescla ficção e jornalismo, revive a angústia de uma mulher que sofre a violência de um assédio sexual, e tem a consciência de sua vulnerabilidade em face da ameaça de estupro. Violência encenada no espaço público, o que demonstra que a mulher é perseguida dentro e fora de casa. Via crucis de um corpo rebaixado à condição de mero objeto sexual a ser apropriado vorazmente pelos homens. Carlos Magno Gomes resume com propriedade a violência descrita no conto:

Assim, "A língua do P" narra um femicídio cometido por estranhos. A violência física e a banalização do crime são expostas como parte do mesmo problema. Tal crime nasce de um desejo masculino de possuir uma passageira de um trem. Na narrativa ficcional, há tanto a violência verbal quanto a física. A autora descreve como o desejo de violência se confunde com o desejo sexual, mostrando as tênues fronteiras desses anseios masculinos. No primeiro momento, há apenas o assédio sexual com palavrões. No segundo, o estupro seguido de assassinato, expondo a suscetibilidade do corpo feminino aos perigos da violência urbana e aos desejos masculinos incontrolados (2013, p. 7-8).

O femicídio (ou feminicídio) resulta de uma visão distorcida sobre a mulher, assentada no desrespeito total aos seus direitos fundamentais e na supremacia da dominação masculina. $\mathrm{O}$ crime violatório de direito das mulheres, típico da violência urbana, é igualmente abordado por Lygia Fagundes Telles no conto "Venha ver o pôr do sol" (2008). A autora contrapõe os dois ex-namorados, Raquel e Ricardo, numa atmosfera mórbida e cria um enredo asfixiante para transmitir a sensação de controle absoluto do homem sobre a mulher. Ricardo é incapaz de aceitar a separação e a perda da amada. O seu plano macabro atesta o domínio e a manipulação do homem como possuidor do corpo da mulher (Gomes, 2013, p. 6-7). 
Convém registrar que a Lei 13.104/2015, de 2015, altera o art. 121 do Código Penal, prevendo o feminicídio como circunstância qualificadora do crime de homicídio, e o art. $1^{\circ}$ da Lei n. 8.072, de 25 de julho de 1990, para incluí-lo no rol dos crimes hediondos. Louva-se a iniciativa legislativa para salvaguardar a integridade física das mulheres. Recorde-se que essa questão foi objeto de deliberação e julgamento perante a Corte Interamericana de Direitos Humanos: o Caso do Campo de Algodão (Caso González e outras (“Campo Algodoeiro”) vs. México). Trata-se, consoante Lucas Lixinski, do homicídio de várias mulheres em Ciudad Juárez, no México. O caso teve repercussão, pois, pela primeira vez, um tribunal internacional reconheceu o termo "feminicídio", responsabilizando o México pelo desaparecimento de três mulheres: Claudia Ivette Gonzalez, Esmeralda Herrera Monreal e Laura Berenice Ramos Monárrez. A sentença foi proferida em 16 de novembro de 2009.

A literatura registra vários episódios de violência contra a mulher, retratados como comportamentos culturais dominantes. De fato, pode-se entender que as leis que criminalizam as violações contra a mulher não têm plena efetividade devido aos persistentes padrões culturais que inferiorizam a mulher, impedindo que elas possam desenvolver a capacidade de serem protagonistas de suas histórias, conforme nos ensina Paul Ricoeur. O mundo é hostil ao florescimento da mulher, prisioneira de uma cultura de dominação masculina. Catharine MacKinnon descreve com realismo o mundo ameaçador em que a maioria das mulheres habita:

As mulheres sabem que o mundo está lá fora porque ele
nos atinge na cara. Literalmente. Somos estupradas,
espancadas, pornografadas, definidas pela força, por um
mundo que começa, pelo menos, inteiramente fora de
nós. Não importa o que pensemos dele, o quanto
tentemos pensar que ele não existe ou pensá-lo em uma
forma diferente para que habitemos, o mundo permanece
real. Experimentem, uma hora dessas. Ele existe
independentemente da nossa vontade. Sabemos que ele
está lá porque, não importa o que façamos, não podemos
sair dele. O poder masculino é, para nós - e portanto é -,
esse tipo de fato (2013, p. 243).

Talvez uma saída para a superação de um mundo tão opressor para as mulheres seja tecer narrativas que possam indicar um caminho de não submissão ao universo masculino. Maria Colasanti apresenta-se sutilmente uma fábula - A moça tecelã - em que o homem é produto do desejo da 
mulher, mas é desfeito devido à cobiça e ao controle sobre a tecelã (2004). Artífice de seu destino, a mulher pode vislumbrar um trajeto de autonomia, reconhecimento e justiça.

\section{CONCLUSÃO}

A conexão filosofia, literatura e direito mostra-se profícua na medida em que instaura um diálogo intenso e desmascarador. Torna-se, com efeito, a possibilidade de vislumbre de um sentido mais humano para o reconhecimento de segmentos sociais subtraídos do convívio em sociedade e do intercâmbio das ideias políticas. $\mathrm{Na}$ investigação feita o enfoque centrou-se na violência cometida contra as mulheres.

O percurso conceitual de Paul Ricoeur leva-nos a atravessar os estratos configuradores do homem capaz, mormente os estágios denominados de homem falante, do homem que age, do homem narrador, e do homem responsável. Instaura-se a fenomenologia hermenêutica da pessoa, proposta por Ricoeur, que irá conduzir à alteridade e à afirmação dos componentes intrínsecos da identidade.

Os marcos teóricos trazidos para uma investigação sobre o sujeito capaz demonstraram a sua perfeita adequação à leitura feita a partir da obra de Lima Barreto e da literatura de autoria feminina, especialmente representada por Clarice Lispector, Lygia Fagundes Telles, Lya Luft e Marina Colasanti. Ao indagar quem é o sujeito do direito, Ricoeur está elevando a discussão para o nível do reconhecimento ético, hábil em identificar o outro como pessoa digna de ser considerada. Busca-se formar um sujeito habilitado a inscrever o seu papel na sociedade, ou seja, a exercer plenamente a cidadania, como condição existencial indispensável para o aperfeiçoamento de seu intelecto e de sua vocação para a política.

Sobretudo, o aporte ricoeuriano permite dar visibilidade ao sujeito de direito, apto a ser estimado e respeitado, e, portanto, a constituir-se em agente ético na reflexão e construção da política, e particularmente na formação de sociedades mais justas. Em decorrência dessas reflexões, destaca-se a necessidade de modelagem de um sujeito de direito plenamente capaz, para a plena concretização dos Direitos Humanos. Este trabalho tem por objetivo precípuo reabilitar o sujeito capaz de pleno 
direito, a palavra tantas vezes silenciada pela imposição da força, e de banir todas as estratégias de exclusão da mulher.

Vimos, com Lima Barreto, como suas crônicas estavam afinadas com a realidade e com o sofrimento de centenas de mulheres sacrificadas por uma mentalidade opressiva e discriminatória. Encontra-se em Lima Barreto o clamor por justiça em diversas crônicas denunciando as atrocidades cometidas contra as mulheres adúlteras.

A análise das obras que compõem o painel da parte intitulada " $A$ via crucis do corpo da mulher: trajetos de violência na literatura de Clarice Lispector, Lygia Fagundes Telles, Lya Luft e Marina Colasanti” reforça a continuidade da violência praticada contra a mulher. Apesar de constituir uma visão panorâmica, os exemplos trazidos comprovam a persistência de uma cultura perversa e desumana no trato com as mulheres.

Sobretudo, o diálogo instaurado permite dar visibilidade ao sujeito do direito, in casu a mulher, apto a ser estimado e respeitado, e, portanto, a constituir-se em agente ético na reflexão e, sobretudo, na formação de sociedades mais justas. E o corpo da mulher aparece como sinal de que a violência e a discriminação devem ser eliminadas para a construção de comunidades mais decentes.

\section{REFERÊNCIAS}

BARRETO, Lima. Artigos: Bagatelas. In: BARRETO, Lima; BARBOSA, Francisco de Assis (Org.); HOUAISS, Antônio; PROENÇA, Antônio e M. Cavalcanti (Cols.). Obras de Lima Barreto. 2. ed. São Paulo: Brasiliense, 1961a. v. 9. (Prefácio de Astrojildo Pereira).

BARRETO, Lima. Artigos e crônica: Vida urbana. In: BARRETO, Lima; BARBOSA, Francisco de Assis (Org.); HOUAISS, Antônio; PROENÇA, Antônio e M. Cavalcanti (Cols.). Obras de Lima Barreto. 2. ed. São Paulo: Brasiliense, 1961b. v. 11. (Prefácio de Antônio Houaiss).

BESSE, Susan K. Modernizando a desigualdade: reestruturação da ideologia de gênero no Brasil, 1914-1940. Trad. de Lólio Lourenço de Oliveira. São Paulo: Editora da Universidade de São Paulo, 1999.

BLAY, Eva Alterman. Violência contra a mulher e políticas públicas. Estudos Avançados, São Paulo, v. 17, n. 49, set. 2003. Available at: $<$ http://www.scielo.br/scielo.php?script=sci arttext\&pid=S0103-4014200 3000300006>. Access: 2 Mar. 2015. 
BRASIL. Lei 11.340/2006, de 07 de agosto de 2006. Cria mecanismos para coibir a violência doméstica e familiar contra a mulher, nos termos do $\S 8$ o do art. 226 da Constituição Federal, da Convenção sobre a Eliminação de Todas as Formas de Discriminação contra as Mulheres e da Convenção Interamericana para Prevenir, Punir e Erradicar a Violência contra a Mulher; dispõe sobre a criação dos Juizados de Violência Doméstica e Familiar contra a Mulher; altera o Código de Processo Penal, o Código Penal e a Lei de Execução Penal; e dá outras providências. Available at: <http://www.planalto.gov.br/ccivil 03/ ato2004-2006/2006/lei/l11340.

htm>. Access: 26 Oct. 2015.

BRASIL. Lei 13.104/2015, de o9 de março de 2015. Altera o art. 121 do Decreto-Lei no 2.848, de 7 de dezembro de 1940 - Código Penal, para prever o feminicídio como circunstância qualificadora do crime de homicídio, e o art. 1o da Lei no 8.072, de 25 de julho de 1990, para incluir o feminicídio no rol dos crimes hediondos. Available at: <http://www.planalto. gov.br/ccivil 03/ At02015-2018/2015/Lei/L13104.htm>. Access: 26 Oct. 2015 .

CANDIDO, Antonio. Direitos humanos e literatura. In: FESTER, Antonio Carlos Ribeiro (Org.). Direitos humanos e... São Paulo: Brasiliense; Comissão Justiça e Paz de São Paulo, 1989.

CANDIDO, Antonio. Vários escritos. 5. ed. Rio de Janeiro: Ouro sobre Azul, 2011.

COLASANTI, Marina. A moça tecelã. São Paulo: Global, 2004.

FACHIN, Melina Girardi. Direitos humanos e fundamentais: do discurso à prática efetiva: um olhar por meio da literatura. Porto Alegre: Nuria Fabris Editora, 2007.

FERNANDES, Ana Helena Cobra. O feminino nas crônicas de Lima Barreto - Rio de Janeiro 1905-1922. In: XVII Encontro Regional de História - O lugar da História. ANPUH/SPUNICAMP. Anais... Campinas: set. 2004. CDROM. Available at: <http://www.anpuhsp.org.br/sp/downloads/CD\%20 XVII/ST\%20XXVII/Ana\%20Helena\%20Cobra\%20Fernandes.pdf $>$. Access: 5 Oct. 2015 .

GINZBURG, Jaime. Literatura e direitos humanos: notas sobre um campo de debates. In: GINZBURG, Jaime. Crítica em tempos de violência. São Paulo: Editora da Universidade de São Paulo, Fapesp, 2012.

GOMES, Carlos Magno. Marcas da violência contra a mulher na literatura. Revista Diadorim - Revista de Estudos Linguísticos e Literários do Programa de Pós-Graduação em Letras Vernáculas da Universidade Federal do Rio de Janeiro, Rio de Janeiro, v. 13, p. 1-11, jul. 2013. Available at: <http://www.revistadiadorim.letras.ufrj.br>. Access: 26 Oct. 2015.

HAVELOCK, Eric Alfred. Prefácio a Platão. Trad. de Enid Abreu Dobránzsky. Campinas: Papirus, 1996.

KAHN, Daniela Mercedes. A via crucis do outro: identidade e alteridade em Clarice Lispector. São Paulo: Associação Editorial Humanitas: Fapesp, 2005 . 
LISPECTOR, Clarice. A língua do "P”. In: LISPECTOR, Clarice. A via crucis do corpo: contos. Rio de Janeiro: Rocco, 1998.

LIXINSKI, Lucas. Caso do Campo de Algodão: Direitos Humanos, Desenvolvimento, Violência e Gênero (Nota de Ensino). Casoteca Direito $G V$ - Produção de Casos 2011. Available at: <http://direitosp. fgv.br/sites/direitosp.fgv.br/files/campo de algodao - nota de ensino. pdf $>$. Access: 28 Nov. 2015.

LUFT, Lya. As parceiras. 30. ed. Rio de Janeiro: Editora Record, 2015.

MacKINNON, Catharine. Desejo e poder. In: MIGUEL, Luis Felipe; BIROLI, Flávia (Org.). Teoria política feminista: textos centrais. Vinhedo, SP: Editora Horizonte, 2013.

MENDONÇA, Adriana Sussekind de. A vida cultural no Rio de Janeiro durante a segunda guerra mundial através do diário do jurista Carlos Sussekind de Mendonça. 123 f. Dissertação de Mestrado (Programa de PósGraduação em Memória Social). Universidade Federal do Rio de Janeiro, Rio de Janeiro, 2013. Available at: <http://www.me moriasocial.pro.br/documentos/Disserta\%C3\%A7\%C3\%B5es/Diss325.pdf> . Access: 2 Mar. 2015.

MIGUEL, Luis Felipe; BIROLI, Flávia (Org.). Teoria política feminista: textos centrais. Vinhedo, SP: Editora Horizonte, 2013.

OKIN, Susan Moller. Justice, gender and the family. New York: Basic Books, 1989.

PLATÃO. A República. 8. ed. Tradução, introdução e notas Maria Helena da Rocha Pereira. Lisboa: Fundação Calouste Gulbenkian, 1996.

RICOEUR, Paul. O si-mesmo como um outro. Trad. de Lucy Moreira Cesar. Campinas, SP: Papirus, 1991.

RICOEUR, Paul. Leituras 2: a região dos filósofos. Trad. de Marcelo Perine e Nicolás Nyimi Campanário; Revisão Luiz Paulo Rouanet. São Paulo: Loyola, 1996.

RICOEUR, Paul. Percurso do reconhecimento. Trad. de Nicolás Nyimi Campanário. São Paulo: Edições Loyola, 2006.

RICOEUR, Paul. O justo1: a justiça como regra moral e como instituição. Trad. de Ivone C. Benedetti. São Paulo: WMF Martins Fontes, 2008.

TELLES, Lygia Fagundes. Venha ver o pôr do sol. In: TELLES, Lygia Fagundes. Venha ver o pôr do sol e outros contos. São Paulo: Ática, 2008.

VASCONCELLOS, Eliane. Entre a agulha e a caneta: a mulher na obra de Lima Barreto. Rio de Janeiro: Lacerda Ed., 1999.

VASCONCELLOS, Eliane. Mais feminista que as feministas. Revista de História da Biblioteca Nacional. Rio de Janeiro, n. 104, maio 2014. Available at: <http://www.revistadehistoria.com.br/secao/leituras/maisfeminista-que-as-feministas $>$. Access: 5 Oct. 2015.

VASCONCELLOS, Eliane. Não as matem. Available at: <http://www.casaruibarbosa.gov.br/dados/DOC/artigos/o-z/FCRB Eliane Vasconcellos Nao as matem.pdf $>$. Access: 5 Oct. 2015. 